\title{
Comparison of B-Mode with B-Flow Sonography for the Evaluation of Femoral Arteries in Infants
}

\section{Vergleich von B-Bild und B-Flow Sonografie zur Evaluation der Femoralarterien bei Säuglingen}

Authors

Michael Groth ${ }^{1}$, Elena Dammann ${ }^{1}$, Florian Arndt' ${ }^{2}$, Marielle Ernst ${ }^{3}$, Jochen Herrmann ${ }^{1}$

Affiliations

1 Department of Diagnostic and Interventional Radiology and Nuclear Medicine, Division of Pediatric Radiology, University Medical Center Hamburg-Eppendorf, Hamburg, Germany

2 University Heart Center Hamburg, Department of Pediatric Cardiology, University Medical Center HamburgEppendorf, Hamburg, Germany

3 Department of Diagnostic and Interventional Neuroradiology, University Medical Center HamburgEppendorf, Hamburg, Germany

Key words

femoral artery, measurement, ultrasound, B-flow sonography, B-mode sonography

received 02.10 .2016

accepted 17.05.2017

Bibliography

DOI https://doi.org/10.1055/s-0043-112249

Published online: 6.7.2017 | Fortschr Röntgenstr 2017; 189: 1161-1167 @ Georg Thieme Verlag KG, Stuttgart · New York, ISSN 1438-9029

\section{Correspondence}

Dr. Michael Groth

Department of Diagnostic and Interventional Radiology, Division of Pediatric Radiology, University Medical Center Hamburg-Eppendorf, Martinistr. 52, 20246 Hamburg, Germany

Tel.: ++49/40/741053712

Fax: $++49 / 40 / 741054964$

groth.michael@googlemail.com

\section{ZUSAMMENFASSUNG}

Ziel Evaluation von Femoralarterien (FA) bei Neugeborenen im Rahmen einer Herzkatheteruntersuchung mittels B-Mode (BMS) und B-Flow Sonographie (BFS) und Vergleich beider Methoden bzgl. Bildqualität und Reliabilität von Diametermessungen.

Material und Methoden Das Studienkollektiv bestand aus 21 konsekutiven Säuglingen, welche einen Ultraschall zur Evalation der FA vor oder nach Herzkatheteruntersuchung erhielten. Die Ultraschalldatensätze wurden von zwei Radiologen ausgewertet. Es wurden Gefäßdiameter sowie die maximal auf einem Ultraschallbild darstellbare Gefäßlänge mittels BMS und BFS vermessen. Zusätzlich wurde die Bildqualiät von einem Radiologen bewertet. Die Statistik umfasste den IntraKlassen-Korrelationskoeffizient, eine Bland-Altman Analyse, Fisher's exakten Test sowie einen t-Test.

Ergebnisse Die Intra- und Interobserverkorrelation war exzellent für BMS $(0,7922$ and 0,6521$)$ sowie BFS $(0,8094$ and 0,7637). Eine Bland-Altman Analyse zeigte mittlere Abweichungen zwischen $+/-0,73 \mathrm{~mm}$ (intraobserver) und für BMS $+/-0,55 \mathrm{~mm}$ (interobserver) sowie $+/-0,83 \mathrm{~mm}$ (intraobserver) und $+/-0,7 \mathrm{~mm}$ (interobserver) für BFS. BFS ermöglicht eine signifikant längere Gefäßabbildung auf einem Ultraschallbild $(3,54+/-0,85$ vs. $2,21+/-0,9 \mathrm{~cm}, \mathrm{p}<0,0001)$. Darüber hinaus war die Bildqualität mit BFS signifikant besser als mit BMS ( $p=0,0043)$.

Schlussfolgerung Da BFS eine exzellente Reproduzierbarkeit bei Gefäßdiametermessungen sowie eine der BMS überlegende Bildqualität zeigt, sollte BFS, falls vorhanden, standardmäßig in Untersuchungsprotokolle integriert werden, wenn realistische Gefäßmessungen und -abbildungen erforderlich sind.

\section{Kernaussagen}

- Die B-Flow Sonographie bietet eine hohe Bildqualität für die Evaluation von Femoralarterien

- Gefäßdiametermessungen können mit der B-Flow Sonographie mit exzellenter Reproduzierbarkeit durchgeführt werden

- Eine ergänzende B-Flow Sonographie der Femoralarterien von Säuglingen wird empfohlen, falls vorhanden

\section{ABSTRACT}

Purpose To evaluate femoral arteries (FAs) in infants in the context of catheter angiography with B-mode (BMS) and B-flow sonography (BFS) and to compare both methods for vessel delineation and reliability of vessel diameter measurements.

Methods 21 consecutive infants who underwent ultrasound for the evaluation of FAs before or after cardiac catheterization were retrospectively included in this study. The diameter of the FAs and the maximum length of the vessel section 
displayed on a single ultrasound plane were recorded by two radiologists for BMS and BFS. The visual image quality was rated by one observer. Statistics included intraclass correlation coefficient, Bland-Altman analysis, Fisher's exact test and t-test.

Results The intraobserver as well as interobserver correlation was excellent for BMS (0.7922 and 0.6521) and BFS (0.8094 and 0.7637$)$. The Bland-Altman analysis revealed limits of agreement for BMS between $+/-0.73 \mathrm{~mm}$ (intraobserver) and $+/-0.55 \mathrm{~mm}$ (interobserver) and for BFS between $+/-0.83 \mathrm{~mm}$ (intraobserver) and $+/-0.7 \mathrm{~mm}$ (interobserver). BFS allowed visualization of a longer stretch of the FA than BMS (length $3.54+/-0.85$ vs. $2.21+/-0.9 \mathrm{~cm}$, $p<0.0001)$. The image quality was significantly higher for BFS ( $p=0.0043)$.

Conclusion Since BFS shows excellent reproducibility for vessel measurements and superior image quality in infants, if available, BFS should be included in standard protocols when realistic measurements are required.

\section{Key Points}

- B-flow sonography offers high image quality for the evaluation of femoral arteries.

- Femoral artery diameter measurements performed with B-flow sonography show excellent reproducibility.

- If available, additional B-flow sonography of femoral arteries in infants is recommended.

\section{Citation Format}

- Groth M, Dammann E, Arndt F et al. Comparison of B-Mode with B-Flow Sonography for the Evaluation of Femoral Arteries in Infants. Fortschr Röntgenstr 2017; 189: 11611167

\section{Introduction}

B-flow sonography (BFS) is a technique for vessel imaging with ultrasound, which was first introduced in 2000 [1]. By boosting moving and suppressing non-moving tissue signals, BFS allows digital-subtraction-like imaging of blood vessels [2]. The technique is based on B-mode images and can depict vessel size true to scale while producing a flow image at the same time. BFS may be superior to color Doppler sonography (CDS) when realistic assessment of vascular anatomy is sought as the latter regularly overestimates true vessel size.

Application of BFS for the imaging of carotid arteries [3, 4], hepatic vasculature [5], renal transplant vasculature [6] and other vascular systems has been reported [7, 8]. However, by reviewing the literature we revealed only two studies dealing with BFS for the imaging of femoral arteries in adults $[9,10]$.

In the pediatric population indication for ultrasound examination of femoral arteries includes evaluation before catheterization [11] as well as suspected complication after femoral artery catheterization [12]. BFS combines information regarding vascular perfusion and patency together with true-to-scale representation. Therefore, the technique may be useful to assess femoral artery anatomy before and after interventional therapy in infants to obtain realistic measurements.

The aim of our study was to compare B-mode sonography (BMS) with BFS with regard to vessel delineation and the interobserver as well as intraobserver reliability of vessel diameter measurements in a population of infants.

\section{Materials and methods:}

\section{Study population}

21 consecutive infants ( 14 girls and 7 boys; mean age: 3.8 months, range: 0 - 12 months), who underwent sonography for the evaluation of the femoral arteries before or after cardiac catheterization, were retrospectively included in this study. The main cardiac diseases/indications for cardiac catheterization are listed in $>$ Table 1. The study has been approved by the local ethics committee and the requirement for informed consent was waived. All examinations were conducted according to the Declaration of Helsinki.

\section{Sonography}

All ultrasound studies were performed by a radiologist with more than seven years of experience (M.G.) using a GE Logiq 9 ultrasound system (GE Medical Systems, Milwaukee, WI, USA) with an ML6 - $15 \mathrm{MHz}$ probe. The ultrasound protocol included the acquisition of BMS and BFS volume scans by tilting the ultrasound probe in the long axis orientation of the femoral arteries straight beneath the inguinal ligament. Additionally, CDS single ultrasound images in the long axis of the femoral arteries were recorded. BMS was performed with a probe frequency of $10 \mathrm{MHz}$, BFS with a frequency of $9 \mathrm{MHz}$, and CDS with a frequency of $9 \mathrm{Mhz}$.

\section{Image analysis}

Evaluation of BMS and BFS movies were performed separately and independently by two observers with more than seven (M.G.) and more than 14 years (J.H.) of experience in sonography. Each reader was blinded to the other observer's assessments. A time interval of four weeks between the reading sessions of BMS and BFS was followed by each observer. To evaluate intraobserver reliability, a second assessment was made by one reader (M.G.). Again a time interval of four weeks was followed for BMS and BFS measurements in an attempt to minimize the recall bias.

The peak systolic diameter of the common femoral artery was measured straight above the femoral bifurcation. For BMS, measurements were performed between the inner layer of the femoral artery [13], and for BFS, the vessel diameter was determined as the distance between the parallel walls of the vessel contrasted by B-flow signals [14] ( Fig. 1). 
- Table 1 Main cardiac diseases/indications for cardiac catheterization in the study population.

- Tab. 1 Kardiale Hauptdiagnosen/Indikationen für eine Herzkatheteruntersuchung der Studienpopulation.

\begin{tabular}{|c|c|}
\hline $\mathbf{n}$ & $\begin{array}{l}\text { Main cardiac disease/indication for cardiac catheteriza- } \\
\text { tion }\end{array}$ \\
\hline 7 & Aortic arch coarctation \\
\hline 4 & Complete atrioventricular septal defect \\
\hline 3 & Transposition of the great arteries \\
\hline 3 & Hypoplastic left heart syndrome \\
\hline 2 & Tetralogy of Fallot \\
\hline 1 & Myocarditis \\
\hline 1 & Bland-White-Garland syndrome \\
\hline
\end{tabular}

Additionally, the maximum length of the vessel section displayed on a single ultrasound plane during the systolic phase was recorded for BMS and BFS ( $\triangleright$ Fig. 1).

Finally, femoral artery diameters were measured again by one of the observers (M.G.) for the datasets that included a single CDS image with representation of the common femoral artery and its bifurcation $(n=15)$.

To evaluate the visual image quality of the femoral artery, a 4-point scale was used by one observer (M.G.) for BFS and BMS: $0=$ common femoral artery not clearly definable; 1 = bifurcation of the common femoral artery not clearly definable; 2 = bifurcation of the common femoral artery clearly definable, but limited contrast; 3 = excellent visualization of the common femoral artery. Vessel patency was rated by using the following 4-point scale: 0 = normal vessel; 1 = total vessel occlusion; 2 = vessel stenosis; 3 = uncertain.

\section{Statistical analysis}

To investigate the interobserver as well as intraobserver correlation and agreement for BMS and BFS measurements, intraclass correlation coefficient (ICC) [15] and Bland-Altman analysis (BAA) [16] were applied. The following ICC interpretation scale was used: poor to fair (below 0.4$)$, moderate $(0.41-0.60)$, excellent $(0.61-0.80)$, and almost perfect $(0.81-1)$ [17]. To compare BMS, BFS, and CDS measurements, Person's correlation coefficient, t-test and BAA were used. Differences in visual image quality were evaluated using Fisher's exact test. Statistical analysis was performed with commercially available software tools (MedCalc for Windows, Mariakerke, Belgium and Excel, Microsoft Corporation, Redmond WA USA).

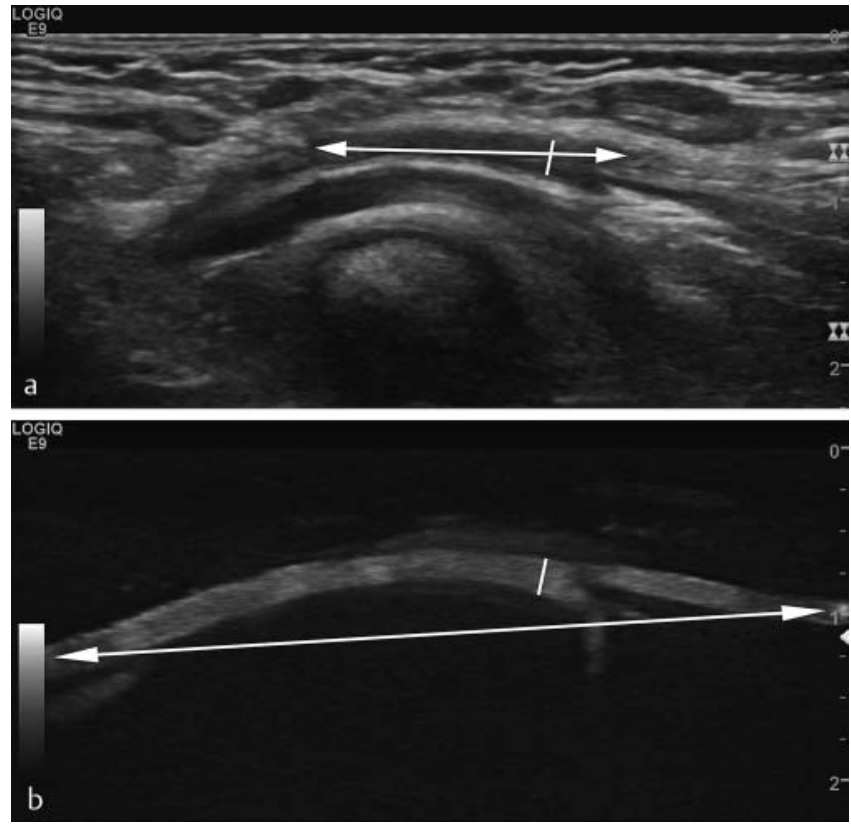

Fig. 1 Vessel diameter and length measurements performed with B-mode $\mathbf{a}$ and B-flow $\mathbf{b}$ sonography in a 5 -month-old boy. $\mathrm{B}$-mode measurements were performed between the inner layer of the femoral artery. For B-flow measurements the vessel diameter was determined as the distance between the parallel walls of the vessel contrasted by B-flow signals.

- Abb. 1 Gefäßdiameter und -längenmessungen mit B-Mode a und B-Flow Sonographie b bei einem 5 Monate alten männlichen Säugling. Gefäßmessungen mit der B-Mode Sonographie wurden zwischen den Innenwänden der Femoralarterie durchgeführt. Messungen mit der B-Flow Sonographie wurden zwischen den parallelen Wänden des sich kontrastierenden Gefäßes durchgeführt.

\section{Results}

\section{Visual evaluation}

BFS revealed vessel occlusion in 3 cases ( $\triangleright$ Fig. 2 ). With BMS, occlusion could be detected in 1 of these cases. In the other 2 cases, discrimination between occlusion and stenosis was not possible. Both BFS and BMS revealed stenosis in 1 case ( $\triangleright$ Fig. 2 ).

The visual image quality was significantly higher for BFS $(p=0.0043)$. The average image quality was $1.4(+/-1.14)$ for BMS and $2.1(+/-0.91)$ for BFS.

\section{BMS versus BFS diameter measurements}

A bias of a greater diameter of $0.29 \mathrm{~mm}$ for BMS compared with BFS was found ( $>$ Fig. 3 ). The correlation between both methods was strong $(r=0.79 ; p<0.00001)$.

\section{BMS versus CDS diameter measurements}

Compared with BMS, CDS revealed a bias of a greater diameter of $0.45 \mathrm{~mm}$ ( $\triangleright$ Fig. 4). Both methods showed a strong correlation $(r=0.79 ; p<0.0005)$. 

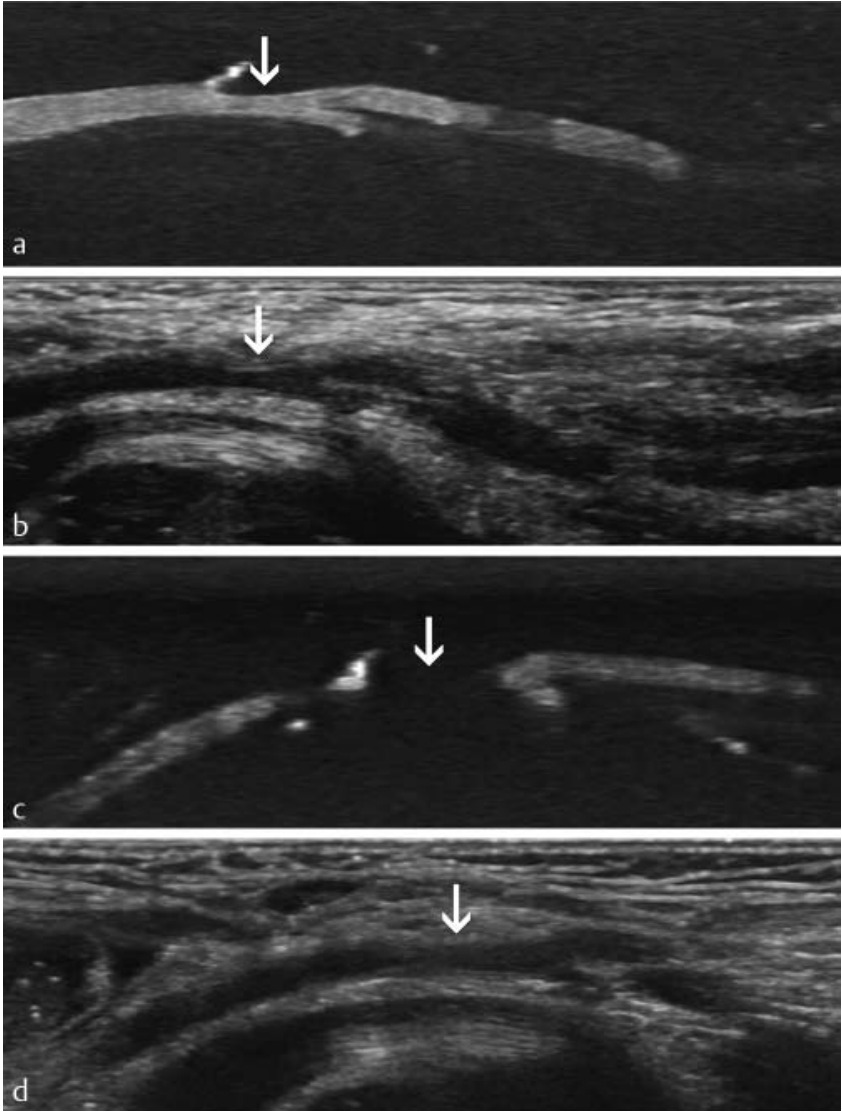

- Fig. 2 Stenosis (arrow in a and b) of the common femoral artery in a 6-month-old girl and femoral artery occlusion (arrow in $\mathbf{c}$ and $\mathbf{d}$ ) in a 6-month-old boy imaged with B-flow (a and $\mathbf{c}$ ) and B-mode sonography (b and d). Both infants underwent cardiac catheterization. In comparison to B-flow, B-mode sonography was not able to differentiate between vessel stenosis and occlusion in $\mathbf{d}$.

- Abb. 2 Stenose (Pfeil in a und b) der Arteria femoralis communis bei einem 6 Monate alten Mädchen und Femoralarterienverschluss (Pfeil in $\mathbf{c}$ und $\mathbf{d}$ ) bei einem 6 Monate alten Jungen mit der B-Flow ( $\mathbf{a}$ und $\mathbf{c}$ ) und B-Mode Sonographie ( $\mathbf{b}$ und $\mathbf{d}$ ). Bei beiden Säuglingen wurde vorher eine Herzkatheteruntersuchung durchgeführt. Im Vergleich zur B-Flow Sonographie war die B-Mode Sonographie nicht in der Lage zwischen Gefäßverschluss und -stenose zu unterscheiden $\mathbf{d}$.

\section{BFS versus CDS diameter measurements}

CDS revealed a bias of a greater diameter of $0.64 \mathrm{~mm}$ compared to BFS. Both methods revealed strong correlation $(r=0.78$; $\mathrm{p}<0.0002)$.

\section{Intraobserver and interobserver reliability}

The intraobserver as well as interobserver correlation was excellent for BMS (ICC: 0.7922 and 0.6521) and BFS (ICC: 0.8094 and $0.7637)$. For BMS, BAA revealed limits of agreement ranging between $+/-0.73 \mathrm{~mm}$ (intraobserver) and $+/-0.55 \mathrm{~mm}$ (interobserver). BFS revealed limits of agreement ranging between $+1-$ $0.83 \mathrm{~mm}$ (intraobserver) and $+/-0.7 \mathrm{~mm}$ (interobserver) ( Fig. 5).

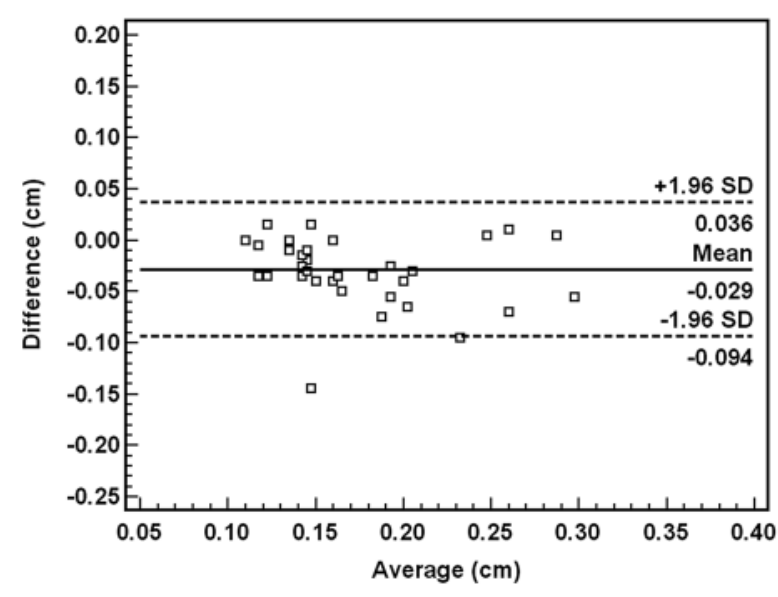

- Fig. 3 Bland-Altman plot of agreement for vessel diameter measurements performed with B-mode versus B-flow (x-axis) sonography.

- Abb. 3 Bland-Altman Graph für Gefäßdiametermessungen mit der B-Mode versus B-Flow (x-Achse) Sonographie.

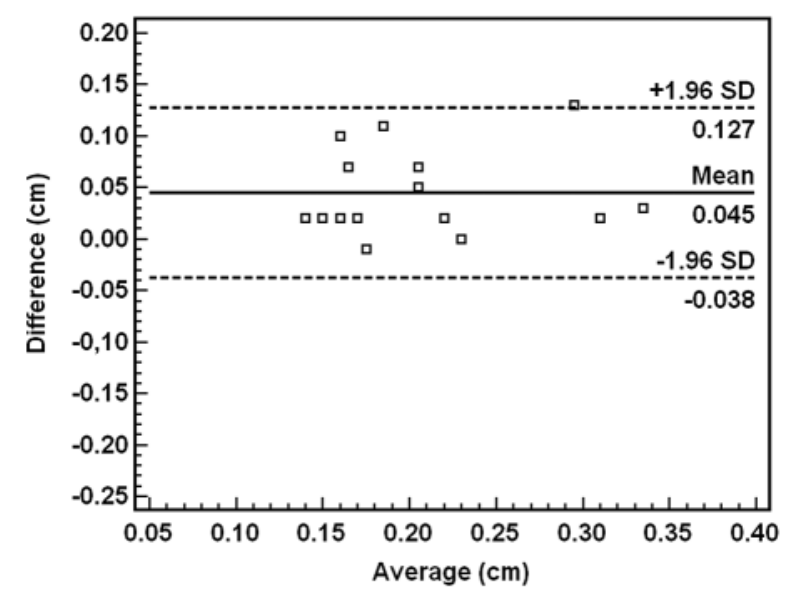

- Fig. 4 Bland-Altman plot of agreement for vessel diameter measurements performed with B-mode versus color Doppler (x-axis) sonography.

- Abb. 4 Bland-Altman Graph für Gefäßdiametermessungen mit der B-Mode versus Color-Doppler (x-Achse) Sonographie.

\section{Comparison of maximum vessel length displayed on a single ultrasound plane by BMS and BFS}

BFS allowed visualization a $1.3 \mathrm{~cm}$ longer stretch of the femoral artery than BMS (length $3.54+/-0.85$ vs. $2.21+/-0.9 \mathrm{~cm}$, $p<0.0001$ ) ( $>$ Fig. 6). 

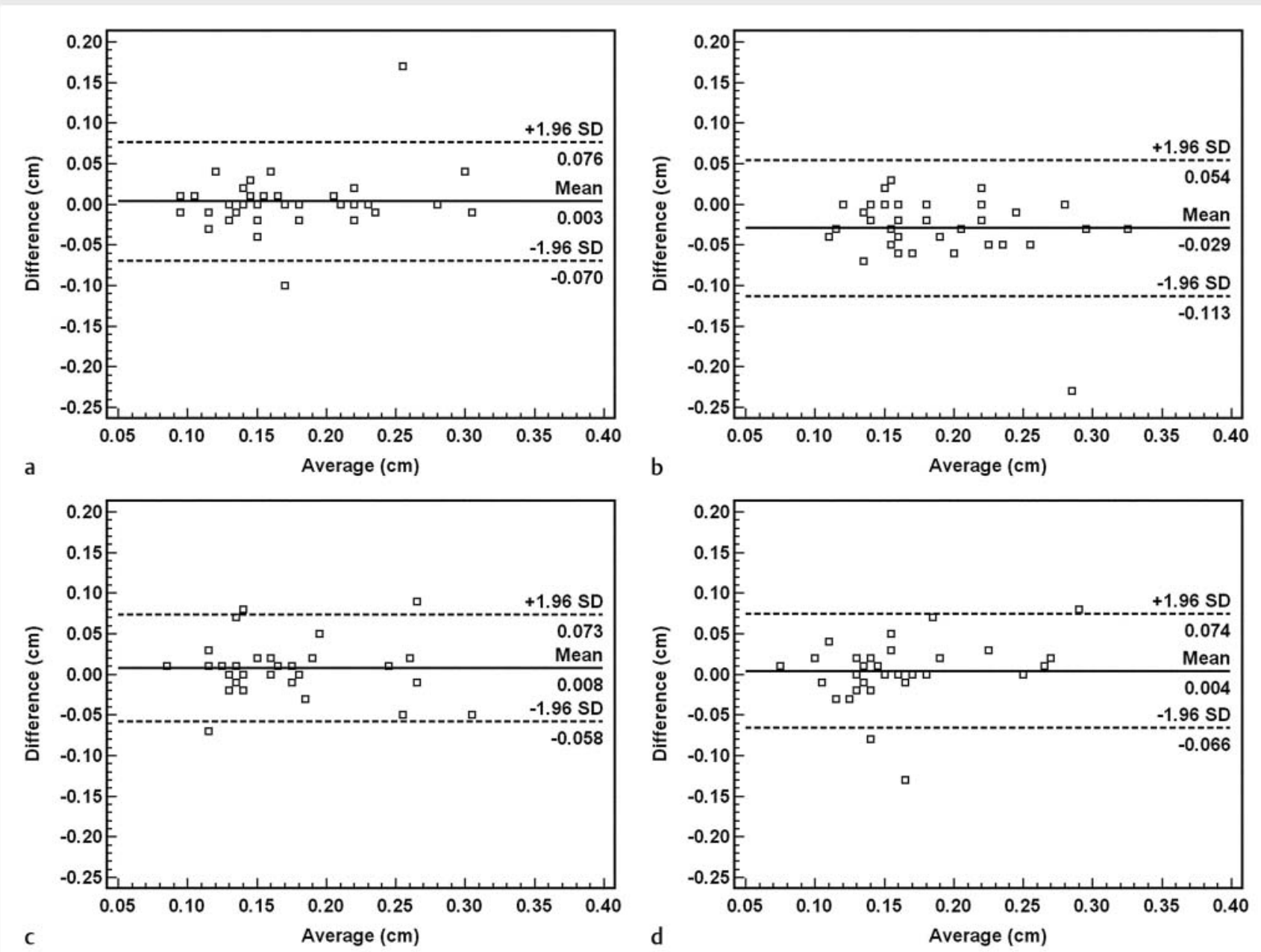

Fig. 5 Bland-Altman plots of intraobserver $\mathbf{a}, \mathbf{b}$ and interobserver agreement $\mathbf{c}, \mathbf{d}$ for vessel diameter measurements performed with B-mode a, $\mathbf{c}$ and B-flow b, $\mathbf{d}$ sonography.

- Abb. 5 Bland-Altman Graphen der Intra- a, b und Interobserverübereinstimmung c, d für Gefäßdiametermessungen mit der B-Mode a, c und B-Flow b, d Sonographie.

\section{Discussion}

This study investigated infants with the ultrasound methods of BMS, BFS, and CDS to obtain realistic measurements of femoral artery size and configuration. Vessel size is age-dependent and varies considerably between individuals. Studies reporting on ultrasound-guided vascular puncture in infants demonstrated lower complication rates [18]. In small children and after repetitive puncture, vascular access should be evaluated in detail and prior to the intervention, since the smallest possible devices should be used to minimize vascular damage [19].

Our study demonstrates that BFS is suitable to obtain true-toscale measurements of femoral arteries in children. The maximum systolic artery diameter assessed with BFS showed only very low differences with respect to the reference standard of BMS. While measurements obtained with BFS are almost equal to BMS, BFS was clearly superior for vessel delineation allowing for coverage of a significantly longer stretch of the artery. This refers to the fact that BFS boosts the contrast of moving tissues like blood and demarcates perfused parts of the vessel [1, 2].

Furthermore, our data demonstrate excellent intraobserver and interobserver reliability of BFS to BMS when volume scans are performed. The major advantage of volume scans is that even someone who did not perform the initial ultrasound is able to evaluate the vessel. This approach is especially useful in a setting where pre-interventional workup and catheter angiography are not performed by the same person or team.

Characterization of post-puncture vascular abnormalities was not the primary focus of this study. Femoral artery occlusion was noted in three pediatric patients and femoral artery stenosis in one patient. Using parallel visual grading, the abnormalities were more distinctly shown by BFS and the technique may be superior to BMS also in the differentiation of postprocedural complications. After cardiac catheterization in children, common complications include femoral artery pseudoaneurysm, arteriovenous fistula, hematoma, arterial stenosis and arterial occlusion 


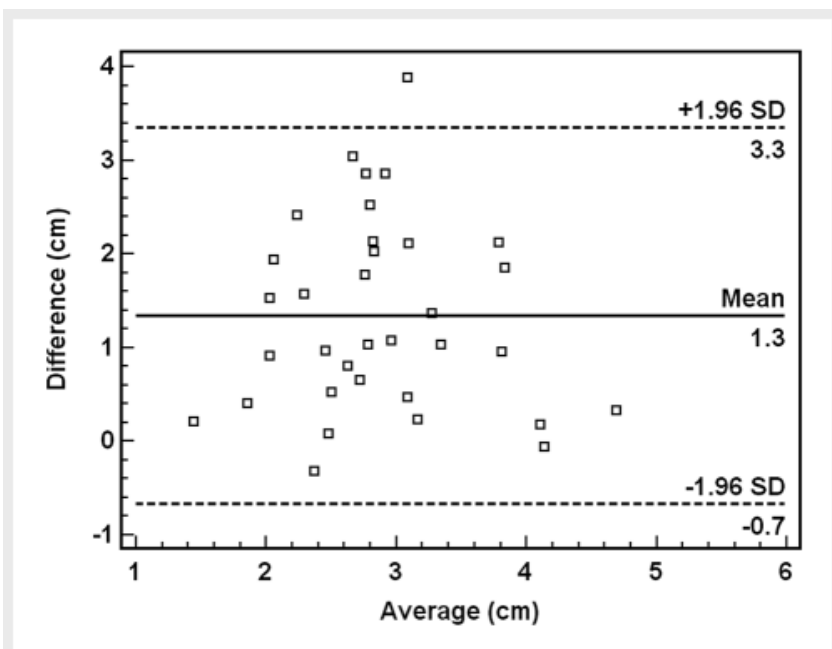

- Fig. 6 Bland-Altman plot comparing the longest stretch of femoral artery visualized with B-flow ( $\mathrm{x}$-axis) and $\mathrm{B}$-mode sonography.

- Abb. 6 Vergleich zwischen B-Flow (x-Achse) und B-Mode Sonographie bzgl. der maximal auf einem Ultraschallbild darstellbaren Gefäßlänge mittels Bland-Altman Graph.

[20 - 22]. Based on clinical examination alone, the diagnosis of femoral artery occlusion after cardiac catheterization in infants is only $4.7 \%$, while the use of Doppler ultrasound leads to a higher detection rate of $18.5 \%$ to $32.4 \%[12,20]$. Therefore, ultrasound should be performed on a regular basis after cardiac catheterization to screen for complications in order to initiate fast treatment [12]. The potential role of BFS in this field has to be addressed in further studies.

Our survey compared CDS measurements with BMS and BFS measurements, as well. Since our ultrasound protocol did not include volume scans of CDS, vessel diameter measurements were performed here on single images. Compared with BMS, the vessel diameter was overestimated by a mean of nearly half a millimeter with CDS. Moreover, in comparison to BFS, overestimation was even more than half a millimeter with CDS. Because the single CDS image was recorded either in a systolic or diastolic phase, the mean bias between CDS and systolic BMS or BFS diameter measurements could have been even higher, if only systolic CDS images were evaluated. Therefore, caution has to be taken when femoral artery diameters are measured with CDS in clinical practice.

\section{Certain limitations of our study have to be addressed}

First, our study included only infants. Since the distance between the ultrasound probe and the femoral artery is shorter than in older children and adults, our data does not allow a statement regarding the utility of BFS in older patients. To the best of our knowledge, only two other studies evaluated BFS for femoral arteries in adults $[9,10]$. These studies demonstrated the feasibility of BFS to detect femoral artery pseudoaneurysm and dissection. However, vessel diameters and stretch coverage were not evaluated. Further studies should analyze the relationship between probe/vessel distance and vessel visualization by BFS and to evaluate possible limitations of BFS in older patients.

Second, there are several methods for measuring vessel diameters with BMS like the outer-to-outer method, where calipers are placed on the outer vessel layer, the inner-to-inner layer, where calipers are placed on the inner vessel layer, and the leading edge-to-leading edge method, where calipers are placed on the outer layer of the anterior and inner layer of the posterior vessel wall [13]. The leading edge-to leading edge method is widely accepted for diameter measurements of vessels like the carotid and femoral artery [23]. Instead of the leading edge-to-leading edge method, we applied the inner-to-inner method for BMS measurements. Since BFS was performed between the parallel walls of the vessel contrasted by B-flow signals, we felt that the inner-to-inner method was the most comparable. A bias of a greater diameter of $0.29 \mathrm{~mm}$ for BMS compared with BFS underlined this assumption.

Third, until now, BFS is offered only by one manufacturer of ultrasound machines and its use is therefore limited to a few institutions. A comparison of BFS with other ultrasound imaging techniques offered by different manufactures like Superb MicroVascular Imaging by Toshiba would be desirable [24]. At the same time, such a comparison is difficult since patients must be examined on different ultrasound machines and the performing institution must be in possession of these machines.

Our study demonstrates BFS to be superior to BMS for displaying longer stretch coverage of the femoral artery and visual image quality in infants. Moreover, diameter measurements performed with BFS showed excellent reproducibility. Therefore, if available, we recommend additional application of BFS for the evaluation of femoral arteries in infants.

\section{Conflict of Interest}

The authors declare that they have no conflict of interest.

\section{References}

[1] Weskott HP. B-flow-a new method for detecting blood flow. Ultraschall in Med 2000; 21: 59-65

[2] Horng A, Reiser M, Clevert DA. Current developments in vascular ultrasound. Radiologe 2009; 49: 998 - 1004

[3] Umemura A, Yamada K. B-mode flow imaging of the carotid artery. Stroke 2001; 32: 2055-2057

[4] Bucek RA, Reiter M, Koppensteiner I et al. B-flow evaluation of carotid arterial stenosis: initial experience. Radiology 2002; 225: 295-299

[5] Wachsberg RH. B-flow imaging of the hepatic vasculature: correlation with color Doppler sonography. Am J Roentgenol 2007; 188: W522W533

[6] Russo E, Cerbone V, Sciano D et al. Posttransplant renal monitoring with B-flow ultrasonography. Transplant Proc 2010; 42: 1127-1129

[7] Hancerliogullari KO, Soyer T, Tosun A et al. Is B-Flow USG superior to Color Doppler USG for evaluating blood flow patterns in ovarian torsion? J Pediatr Surg 2015; 50: 1156-1161

[8] Zhang D, Zhang Y, Ren W et al. Prenatal Diagnosis of Fetal Interrupted Aortic Arch Type A by Two-Dimensional Echocardiography and FourDimensional Echocardiography with B-Flow Imaging and Spatiotemporal Image Correlation. Echocardiography 2015; 33: 90 - 98 
[9] Jung EM, Lutz R, Clevert DA et al. B-Flow: sonographic assessment and therapy for femoral artery pseudoaneurysm. Rofo 2001; 173: 805-809

[10] Clevert DA, Rupp N, Reiser M et al. Improved diagnosis of vascular dissection by ultrasound B-flow: a comparison with color-coded Doppler and power Doppler sonography. Eur Radiol 2005; 15: 342 - 347

[11] Kroger K, Nettelrodt ], Muntsches C et al. Impact of age, height, and body mass index on arterial diameters in infants and children: a model for predicting femoral artery diameters prior to cardiovascular procedures. J Endovasc Ther 2004; 11: 419-423

[12] Knirsch W, Kellenberger C, Dittrich S et al. Femoral arterial thrombosis after cardiac catheterization in infancy: impact of Doppler ultrasound for diagnosis. Pediatr Cardiol 2013; 34: 530 - 535

[13] Gurtelschmid M, Bjorck M, Wanhainen A. Comparison of three ultrasound methods of measuring the diameter of the abdominal aorta. Br J Surg 2014; 101: 633-636

[14] Oktar SO, Yucel C, Karaosmanoglu D et al. Blood-flow volume quantification in internal carotid and vertebral arteries: comparison of 3 different ultrasound techniques with phase-contrast MR imaging. AJNR Am J Neuroradiol 2006; 27: $363-369$

[15] Costa-Santos C, Bernardes ], Ayres-de-Campos D et al. The limits of agreement and the intraclass correlation coefficient may be inconsistent in the interpretation of agreement. J Clin Epidemiol 2011; 64: 1049

[16] Bland JM, Altman DG. Statistical methods for assessing agreement between two methods of clinical measurement. Lancet 1986; 1: $307-310$
[17] Landis JR, Koch GG. The measurement of observer agreement for categorical data. Biometrics 1977; 33: 159-174

[18] Schwemmer U, Arzet HA, Trautner $\mathrm{H}$ et al. Ultrasound-guided arterial cannulation in infants improves success rate. Eur J Anaesthesiol 2006; 23: $476-480$

[19] Hollinger I, Mittnacht A. Cardiac catheterization laboratory: catheterization, interventional cardiology, and ablation techniques for children. Int Anesthesiol Clin 2009; 47: 63 - 99

[20] Brotschi B, Hug MI, Kretschmar O et al. Incidence and predictors of cardiac catheterisation-related arterial thrombosis in children. Heart 2015; 101: $948-953$

[21] Vitiello R, McCrindle BW, Nykanen D et al. Complications associated with pediatric cardiac catheterization. J Am Coll Cardiol 1998; 32: 1433 1440

[22] Lin PH, Dodson TF, Bush RL et al. Surgical intervention for complications caused by femoral artery catheterization in pediatric patients. J Vasc Surg 2001; 34: 1071 - 1078

[23] Wikstrand J. Methodological Considerations of Ultrasound Measurement of Carotid Artery Intima-Media Thickness and Lumen Diameter. In: Nicokaides A, ed; Ultrasound and Carotid Bifurcation Atherosclerosis. London Dordrecht Heidelberg New York: Springer; 2012: 165-176

[24] Machado P, Segal S, Lyshchik A et al. A Novel Microvascular Flow Technique: Initial Results in Thyroids. Ultrasound Q 2016; 32: 67 - 74 